\title{
An Exercise in Cross-Validation of Data on Employment and Unemployment
}

\author{
Inamdar NIRAD ${ }^{\star}$
}

\begin{tabular}{l}
\hline \multicolumn{1}{c}{ A R T I C L E I N F O } \\
\hline Article history: \\
Accepted September 2019 \\
Available online December 2019 \\
\hline JEL Classification \\
J82, J21, J16, 015, 012 \\
Keywords: \\
Cross-validation of data, Women's \\
employment, Unemployment, \\
NSSO, IHDS-II
\end{tabular}

Since 1950, the National Sample Survey Office (NSSO) has provided demographic and socioeconomic data on India. This has been the basis for academic research in economics, sociology and political science, which in turn, has influenced administrative policy formulation. Considering the widespread implications of such policies, it is vital that the underlying research data are accurate. Hence, academicians have paid a lot of attention towards designing frameworks to test for validity of data. In particular, a number of papers provide methodologies to compare and cross-validate two data sources. While all these papers present detailed findings, we observe that in the available literature, no researcher has compared NSSO \& IHDS with respect to employment and unemployment. We recognise that this is a vital socioeconomic issue, affecting nearly 1 billion citizens of India. Therefore, this paper compares the two sources in a similar time period (2011 - 2012), to bring out the similarities \& differences on the data. In particular, we will examine whether the prime factors affecting employment \& unemployment are the same.

\section{Literature review}

Minhas (1988) compares the NSSO estimates of household expenditure \& the independent data on private consumption from the National Accounting System (NAS). It attempts to - (a) investigate the scientific rationale behind these comparisons, (b) indicate the weaknesses and strengths of the external validator data set as a touchstone to assess the reliability of the NSSO estimates, (c) assess the degree of cross-validation, or the lack of it, between the two sets relating to two years, and (d) draw some lessons for improving the two data sets as well as caution against their incorrect uses.

On similar lines, Bhattacharya (2003) provides a methodology to compare two different datasets from the banking industry in India. In particular, it examines the validity of the BankScope database by comparing results based on it to those obtained from the population-level data for India disseminated by the Reserve Bank of India (RBI). The paper finds that despite good coverage and minor reporting errors, there is strong evidence of selectivity bias in the BankScope data. Choudhury (2002) attempts to identify the extent and nature of potential selectivity biases in samples drawn Prowess, which is a firm-level database on Indian

A B S T R A C T
This paper compares two well-known resources of socioeconomic data of India - one from
National Sample Survey Office (NSSO) $68^{\text {th }}$ round and one from India Human Development
Survey $2^{\text {nd }}$ round (IHDS-II). Academic research hinges on validation of underlying data,
especially in the socioeconomic field, since it can have Government policy implications. This
study compares the two data sources from the same time frame (2011 - 2012) on relevant
parameters pertaining to employment and unemployment. In particular, for the greater
part of the study, we focus on women. First, we identify some factors influencing the labour
force participation rate (LFPR) and stock of persons' unemployment rate (SPUR) of women
- sector, marital status, education, relation to household head, religion, social group and
household size. We perform a series of Probit analyses these separately to determine which
factors are significant for LFPR and SPUR. Then, we combine and include their interaction
effects. At every step, we compare the results from NSSO and IHDS-II to cross-validate
them. We find that for LFPR, both data sources give similar results that all variables are
significant, but for SPUR, they give different results. Finally, we perform Kolmogorov-
Smirnov (K-S) tests and observe that both samples are normally distributed. However,
given the disparity of results in a majority of analyses, one cannot say that the two data
sources are similar. Therefore, in the absence of cross-validation of data from NSSO \& IHDS-
II, the scope for further research is to include a third data source and derive results from
similar analyses. Finally, a comprehensive study would entail proposing a consolidated
model, based on three sources.

(C) 2019 EAI. All rights reserved. 
Industry. Centre for Monitoring Indian Economy (CMIE), a private organisation, compiles this database. The research shows that due to non-random selection of samples, such data could be prone to selectivity biases.

Hirway (2002) analyses the validity of the NSSO data. It says that, the concepts and methods of NSSO are not able to capture work of the poor, particularly of women, satisfactorily. The workforce in certain 'difficult to measure sectors', such as subsistence work, home-based work or informal work, can be better captured through time use surveys (TUS). Using data from the pilot time use survey (1998-99), this paper shows that (a) this survey technique is of getting more realistic estimates of workforce and (b) some of the work not captured in NSSO surveys but captured in the time use surveys is likely to explain the changes in the employment situation in the nineties to a considerable extent. So, in the last two decades, there has been an ongoing debate about the validity of NSSO as a credible source. Scholars have pointed its shortcomings out.

Although NSSO is the most established data collection organisation in India, doubts persist about its level of accuracy. In a bid to overcome some of these questions, other institutions also conduct their own data collection exercises. One such is India Human Development Survey (IHDS), a collective effort of researchers from the University of Maryland and the National Council of Applied Economic Research (NCAER), New Delhi. In a similar effort as the papers mentioned above, Oldiges (2012) specifically compares NSSO \& IHDS on the parameter of per capita cereal consumption (PCCC). It divides the population into numerous brackets, representing different ranges of percentiles as per mean per capita expenditure (MPCE). It notes the difference in the methodologies that whereas NSSO defines MPCE for a monthly period, IHDS-II defines for a mixed recall period. Chancel \& Piketty (2017) compares these two datasets with respect to income equality.

\section{Description of data}

The data are in two groups. One group is from the official Government of India source, National Sample Survey Office (NSSO) 68 ${ }^{\text {th }}$ round $(2011$ - 2012). Particularly, we refer to Schedule 10 on 'Employment and Unemployment' and in particular, we focus on two files, which are called Block 4 (Demographic particulars of household members) and Block 5.1 (Usual Principal Status). The second group is from India Human Development Survey-II (IHDS-II), a nationally representative, a multi-topic survey of 42,152 households in 1,420 villages and 1,042 urban neighbourhoods across India. The goal of IHDS is to document changes in the daily lives of Indian households in an era of rapid transformation.

Both groups have two vital variables, one to identify a household and one to identify a member within a household. A combination of these gives us information on each individual. For both groups, we create a proxy variable for level of education, to shrink the number of categories to 3 . This will make the analysis concise. The 3 categories are - 'niraakshar' (literally meaning 'illiterate or equivalent'), 'shaala' (literally meaning 'school or equivalent') and 'dip/grad' (which is equivalent to 'a diploma or higher certificate'). This proxy variable is the same as in Inamdar (2018).

Regarding the dependent variables, both NSSO \& IHDS-II contain information on the usual status of each individual. From this, we derive two dependent variables - lfp \& unemp, which stand for labour force participation (LFP) and unemployed respectively. If usual_status is 'employed' or 'unemployed', it implies that LFP is 1 (indicates 'participation'), else if the value is 'out of labour force', LFP is 0 (indicates 'non participation'). Among those who participate, some may be unemployed. Only in those cases, unemp is 1 . The following table shows the corresponding coding.

Table 1. Derivation of values of dependent variables from usual status

\begin{tabular}{|l|c|c|}
\hline usual_status & Derived value of LFP & Derived value of unemp \\
\hline Employed & 1 & 0 \\
\hline Unemployed & 1 & 1 \\
\hline Out of labour force & 0 & 0 \\
\hline
\end{tabular}

Considering the main motivation of this paper to compare and cross-validate data sources, we have taken care to see that both sets have the same context in terms of the time period $(2011-2012)$ and similar coverage (all states of India). Since our area of interest is employment and economic activities, we restrict our study to potential earning individuals i.e. those in the age bracket of $15-64$. The following table compares the salient elements of the designs of the two surveys.

Table 2. Comparison of salient elements of survey designs

\begin{tabular}{|l|l|c|c|}
\hline Design element & \multicolumn{1}{|c|}{ Parameter } & NSSO & IHDS-II \\
\hline Respondents & Rural households & 59,700 & 27,579 \\
\hline Respondents & Urban households & 42,024 & 14,573 \\
\hline Respondents & Total households & $\mathbf{1 0 1 , 7 2 4}$ & $\mathbf{4 2 , 1 5 2}$ \\
\hline Respondents & Women & 280,763 & 135,118 \\
\hline Respondents & Men & 176,236 & 69,450 \\
\hline Respondents & Total respondents & $\mathbf{4 5 6 , 9 9 9}$ & $\mathbf{2 0 4 , 5 6 9}$ \\
\hline
\end{tabular}




\begin{tabular}{|l|l|c|c|}
\hline Design element & \multicolumn{1}{|c|}{ Parameter } & NSSO & IHDS-II \\
\hline Time period & Year & $2011-2012$ & $2011-2012$ \\
\hline Coverage & Areas / locations & All Indian states & All Indian states \\
\hline Methodology & Sampling & $\begin{array}{c}\text { Stratified random } \\
\text { sampling }\end{array}$ & $\begin{array}{c}\text { Stratified random } \\
\text { sampling }\end{array}$ \\
\hline
\end{tabular}

\section{Comparative analysis}

We bifurcate our comparative study, which makes it better to present the results. The first part contains descriptive statistics in the form of graphs. It helps to set the context of the comparison to follow. Here, we include both, female and male genders. The second part contains a list of tables, which show calculations of certain parameters based on statistical analysis. Here, we focus mainly on females within the sample sets and conduct deeper studies on two important problems - labour force participation (LFP) and unemployment.

\section{Sub-section 4A - Graphs of basic parameters}

1. Coverage - households

Table 3. Coverage of households (rural and urban)

\begin{tabular}{|l|c|c|c|c|}
\hline Households & \multicolumn{2}{|c|}{ NSSO } & \multicolumn{2}{c|}{ IHDS-II } \\
\hline Rural & 59,700 & $58.7 \%$ & 27,579 & $65.4 \%$ \\
\hline Urban & 42,024 & $41.3 \%$ & 14,573 & $34.6 \%$ \\
\hline Total & $\mathbf{1 0 1 , 7 2 4}$ & $\mathbf{1 0 0 \%}$ & $\mathbf{4 2 , 1 5 2}$ & $\mathbf{1 0 0 \%}$ \\
\hline
\end{tabular}

With a rather high (nearly 7\%) difference in the split between rural and urban households, we expect differences from the two in the results on various parameters. One must state that although the absolute number of households in one survey is more than double that in the other survey, this difference is immaterial. As Singh (2018) says, the effect of size is marginal at most. The smaller survey also has a sizeable sample size, which allows for testing of statistical significance.

\section{Coverage - individuals}

Table 4. Coverage of individuals (rural and urban)

\begin{tabular}{|l|c|c|c|c|}
\hline Individuals & \multicolumn{2}{|c|}{ NSSO } & \multicolumn{2}{c|}{ IHDS-II } \\
\hline Rural & 280,763 & $61.4 \%$ & 135,118 & $66.1 \%$ \\
\hline Urban & 176,236 & $38.6 \%$ & 69,450 & $33.9 \%$ \\
\hline Total & $\mathbf{4 5 6 , 9 9 9}$ & $\mathbf{1 0 0 \%}$ & $\mathbf{2 0 4 , 5 6 9}$ & $\mathbf{1 0 0 \%}$ \\
\hline
\end{tabular}

In terms of individuals also, NSSO has a sample size of more than twice that of IHDS-II. Here, the difference in the split between rural and urban is smaller (5\%). We observe that for IHDS-II, the split between rural and urban is similar at an individual level and at a household level. But, in NSSO, there is a $3 \%$ difference in the split between rural and urban at an individual level and at a household level. In this sense, the smaller survey seems more reliable.

2. Potential earners (ages $15-64$ )

Table 5. Number of potential earners (rural and urban)

\begin{tabular}{|l|c|c|c|c|}
\hline Individuals & \multicolumn{2}{|c|}{ NSSO } & \multicolumn{2}{c|}{ IHDS-II } \\
\hline Rural & 182,683 & $60.2 \%$ & 84,703 & $63.9 \%$ \\
\hline Urban & 120,682 & $39.8 \%$ & 47,821 & $36.1 \%$ \\
\hline Total & $\mathbf{3 0 3 , 3 6 5}$ & $\mathbf{1 0 0} \%$ & $\mathbf{1 3 2 , 5 2 4}$ & $\mathbf{1 0 0 \%}$ \\
\hline
\end{tabular}

Since this study is related to economic activities, one must consider only those individuals in the age bracket of 15 years - 64 years. Just like the terminology in Inamdar (2018), this study shall use the terminology of 'potential earners'. The difference in the split between rural and urban narrows down further to about 3\%. Here, we see that both NSSO and IHDS-II are consistent in terms of the rural-urban split in the general sample (all age groups) and the restricted sample (age groups $15-64$ ). So, we feel that the two datasets are comparable. 
3. Employment status (ages $15-64$ )

Table 6. Split of potential earners as per 'usual status'

\begin{tabular}{|l|c|c|c|c|}
\hline Individuals & \multicolumn{2}{|c|}{ NSSO } & \multicolumn{2}{c|}{ IHDS-II } \\
\hline Employed & 151,901 & $50.1 \%$ & 64,893 & $49.0 \%$ \\
\hline Unemployed & 6,185 & $2.0 \%$ & 2,776 & $2.1 \%$ \\
\hline $\begin{array}{l}\text { Out of labour } \\
\text { force }\end{array}$ & 145,279 & $47.9 \%$ & 64,855 & $48.9 \%$ \\
\hline Total & $\mathbf{3 0 3 , 3 6 5}$ & $\mathbf{1 0 0} \%$ & $\mathbf{1 3 2 , 5 2 4}$ & \\
\hline
\end{tabular}

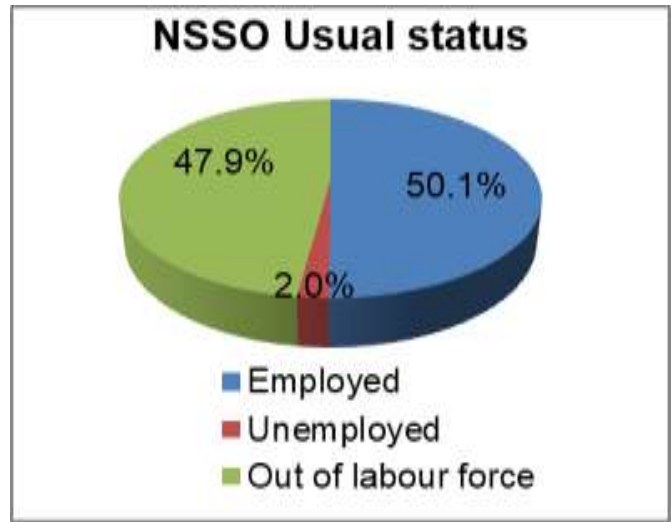

Figure 1. Usual status as per NSSO

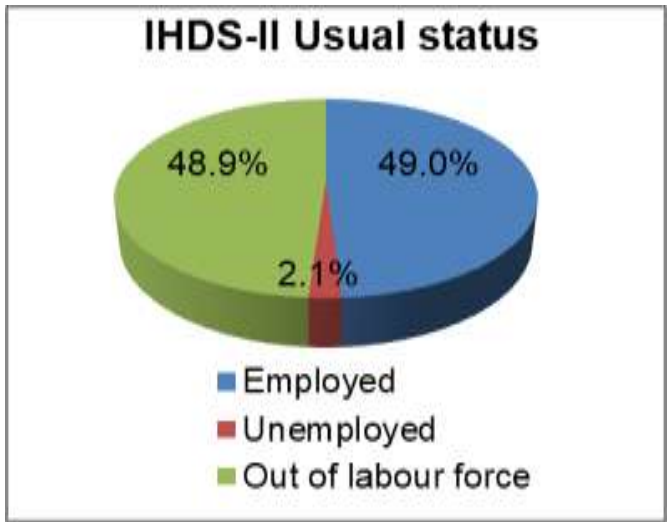

Figure 2. Usual status as per IHDS-II

For the restricted sample of potential earners, the proportions of employed, unemployed and out of labour force are very similar, with less than $1 \%$ difference. Thus, with respect to 'employment status', both the surveys are comparable.

4. LFPR \& SPUR calculations (ages $15-64$ )

Table 7. Labour Force Participation Rate and Stock of Persons Unemployment Rate

\begin{tabular}{|l|c|c|}
\hline Individuals & NSSO & IHDS-II \\
\hline LFPR & $52.1 \%$ & $51.1 \%$ \\
\hline SPUR & $3.9 \%$ & $4.1 \%$ \\
\hline
\end{tabular}

Labour Force Participation Rate $($ LFPR) $=$ (Number of employed + Number of unemployed $) /$ Total population

Stock of Persons Unemployment Rate (SPUR) $=($ Number of unemployed $) /($ Number of employed + Number of unemployed)

Since both datasets have very similar values of LFPR and SPUR, with a negligible difference, one can say that there is validation of the two.

5. Employment statuses of women \& men (ages 15 - 64)

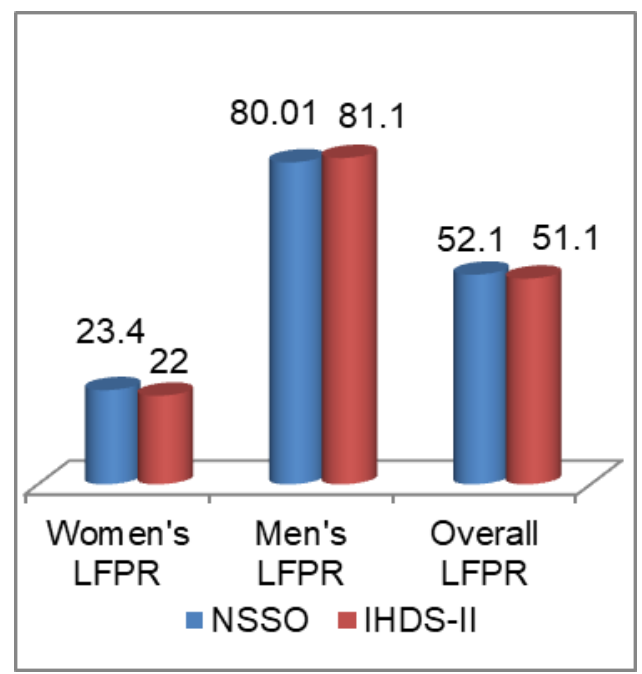

Figure 3. LFPR (percent)

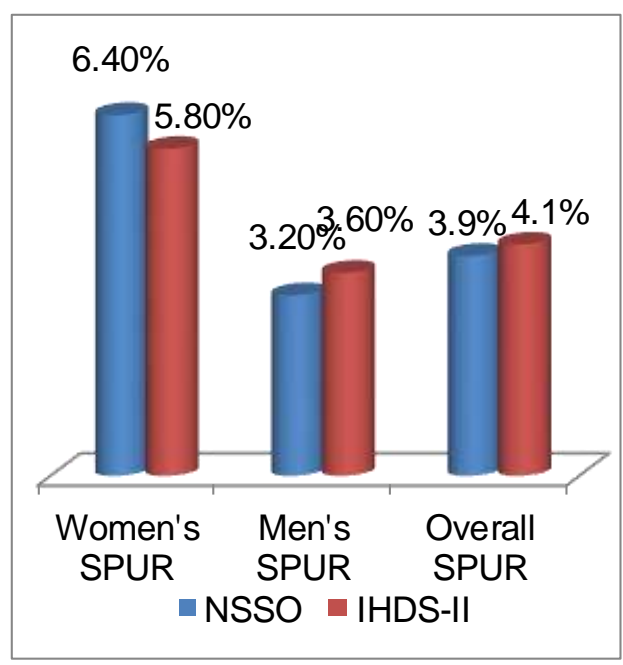

Figure 4. SPUR (percent) 
This corroborates numerous studies highlighting the stark difference between LFPRs of women and men. Similarly, there is a stark difference between SPURs of women and men. Hence, it establishes a strong reason to study the economic activities of women separately. So, we restrict our study to women.

\section{Income estimate}

Next, we look at comparisons of estimates of income and compare three different parameters in this. First is the estimate of all 'potential earners' (ages 15 - 64) at a national level. Next is all potential earners at a state level. In particular, we look at the Indian state of Maharashtra, which is at the forefront when it comes to contribution to the national gross domestic product (GDP). Lastly, we compare the estimates exclusively for women at an all-India level, since that is the focus of this study. Note that NSSO and IHDS-II estimates of income follow different definitions and methodologies. So, the comparison between the two is not direct.

NSSO reports total earnings for a particular week for individuals. In as many as 265,678 (i.e. about $87 \%$ ) cases, there are null values, hence, we ignore these cases for our calculations. Despite that, we have 37,787 cases with values, which are sufficient for statistical analysis. NSSO reports wages (cash plus kind) on a weekly basis and also mentions that on an average, each person is employed for 10 months in a year. On this basis, we multiply the weekly wages by 40 (equivalent to 40 weeks per year) to get the average annual income.

NSSO annual income (per individual) $=$ NSSO weekly income $* 40$

IHDS-II gives the annual income of the entire household. It does not report individual income estimates. So, we adjust the per capita income of the household by taking into account only potential earners. The calculation is below.

1. Potential earners $=$ Number of citizens in the age group of $15-64$

2. Effective individual income $=$ Household income / Potential earners

Simply dividing the household income by the household size (number of members) gives misleading results, since some members of every household are outside the earning age range.

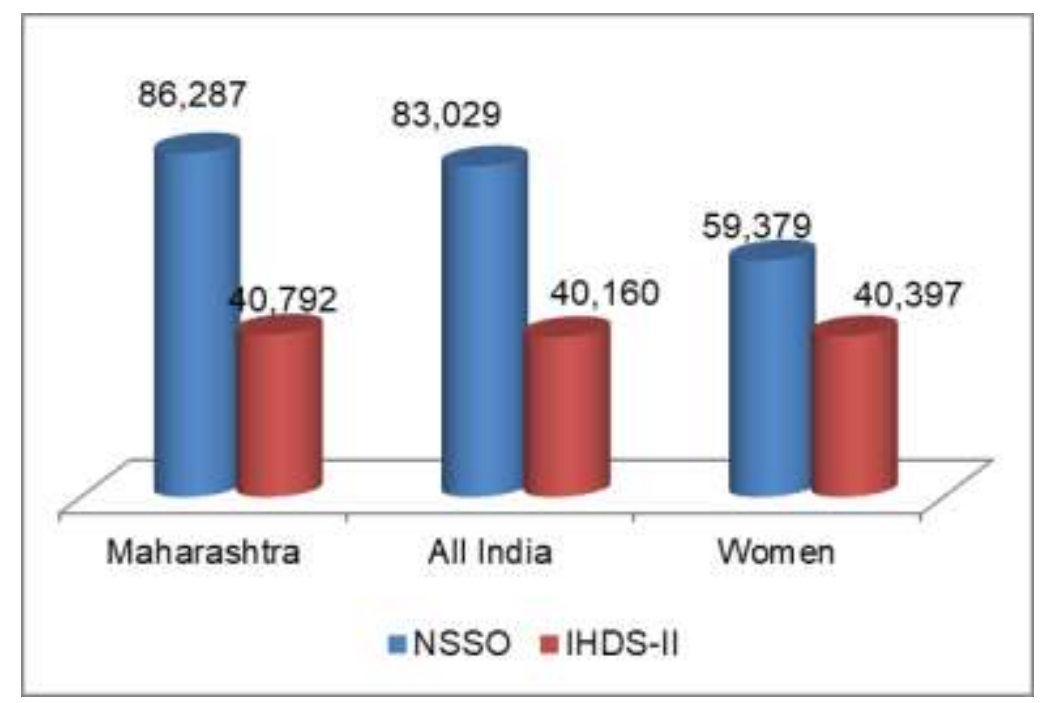

Figure 5. Estimates of average annual income (Rs.)

There is significant variation in the figures from the two sources, in absolute terms, with the NSSO estimates being more than double those of IHDS-II. Both say that the Maharashtra average income is higher than the national average income. The ratios of the former to the latter is 104\% in the case of NSSO and $102 \%$ in the case of IHDS-II, which are very similar. However, the estimates of women's average differ vastly on two counts. Firstly, the women's average is lower in NSSO, while it is slightly higher in IHDS-II. Secondly, the ratio of women's average to the overall average is 78\% for NSSO and $102 \%$ for IHDS-II. So, with respect to income, the datasets are different. Another factor which could partly account for this disparity is that the latter source has a much higher concentration of rural households $(65 \%)$ than the former (58\%). The average income in bound to be lower in this sector. There is also the distinct possibility of under-reporting of earnings on the part of respondents, to maintain secrecy.

Table 8. Income estimates and ratios with respect to national average

\begin{tabular}{|c|c|c|c|c|}
\hline & NSSO & & IHDS-II & \\
\hline & Income & Ratio & Income & Ratio \\
\hline Maharashtra avg. & 86,287 & $104 \%$ & 40,792 & $102 \%$ \\
\hline National avg. & 83,029 & $100 \%$ & 40,160 & $100 \%$ \\
\hline Women avg. & 59,379 & $72 \%$ & 40,397 & $101 \%$ \\
\hline
\end{tabular}




\section{Sub-section 4B - Tables for LFPR statistical analysis}

Having compared various parameters at an aggregate level, now, we restrict our study on women. From the income table and from previous literature, we know that from a social and economic perspective, women are vastly dissimilar to men. That is why in this sub-section, we focus on comparing parameters pertaining to the economic activities of women. The two important metrics to consider are LFPR and SPUR and the key factors which affect these two are - sector, marital status, education level, relation to the household head, religion, social group and household size. Of these, only the last one is an integer (parametric) variable, the others are all categorical (non-parametric).

We perform Probit analysis on LFPR \& SPUR separately. In each case, we compare the results of NSSO \& IHDS-II.

\section{Determination of overall significance of factors for LFPR}

First, we take each of the 7 factors, one at a time and run separate Probit tests, with LFPR as the dependent variable.

Comparison of Probit results using individual variables

Table 9. Results of Probit analysis to test for variables significant for LFPR

\begin{tabular}{|c|c|c|c|c|}
\hline & \multicolumn{2}{|c|}{ NSSO } & \multicolumn{2}{c|}{ IHDS-II } \\
\hline & $\mathrm{X}^{2}$ & Signif & $\mathrm{X}^{2}$ & Signif \\
\hline Sector & 841.726 & 0.000 & 437.383 & 0.000 \\
\hline Marital & 3006.943 & 0.000 & 3872.388 & 0.000 \\
\hline Education & 3345.774 & 0.000 & 704.892 & 0.000 \\
\hline $\begin{array}{c}\text { Relation to } \\
\text { head }\end{array}$ & 5166.559 & 0.000 & 2521.498 & 0.000 \\
\hline Religion & 2310.034 & 0.000 & 168.472 & 0.000 \\
\hline Social group & 1812.402 & 0.000 & 754.981 & 0.000 \\
\hline $\begin{array}{c}\text { Household } \\
\text { size }\end{array}$ & 59.707 & 0.000 & 242.033 & 0.000 \\
\hline
\end{tabular}

All factors are significant, but there is a lot of variation in the $\mathrm{X}^{2}$ values from the two datasets. Only for 'marital status', the values are similar to each other. Since all variable are significant, we can say that both datasets give similar results.

\section{Identification of categories significant for LFPR}

The earlier test assessed the relative importance of each factor at an overall level. Next, we perform ttests using individual variables, by breaking each categorical variable into its various categories. This will help to determine respective coefficients.

Table 10. t-test for LFPR using values of the sector variable

a) Decomposition of variable categories - Sector

\begin{tabular}{|c|c|c|c|c|c|c|}
\hline LFPR & \multicolumn{3}{|c|}{ NSSO } & \multicolumn{3}{c|}{ IHDS-II } \\
\hline $\begin{array}{c}\text { sector }= \\
\text { rural }\end{array}$ & t stat & std. err & Signif & t stat & std err & Signif \\
\hline $\begin{array}{c}\text { sector }= \\
\text { urban }\end{array}$ & n/a & n/a & n/a & n/a & n/a & n/a \\
\hline
\end{tabular}

With 'urban' as the reference, both NSSO and IHDS-II show that rural is significant for LFPR and their coefficients are very similar.

Table 11. t-test for LFPR using values of the marital status variable

b) Decomposition of variable categories - Marital status

\begin{tabular}{|c|c|c|c|c|c|c|}
\hline LFPR & \multicolumn{3}{|c|}{ NSSO } & \multicolumn{3}{|c|}{ IHDS-II } \\
\hline & t stat & std. err & Signif & t stat & std err & signif \\
\hline $\begin{array}{l}\text { marital = } \\
\text { divorced/ } \\
\text { separated }\end{array}$ & 10.329 & 0.0426 & 0.000 & -9.390 & 0.0459 & 0.000 \\
\hline $\begin{array}{l}\text { marital = } \\
\text { married }\end{array}$ & -43.185 & 0.0135 & 0.000 & -11.000 & 0.017 & 0.000 \\
\hline $\begin{array}{l}\text { marital = never } \\
\text { married }\end{array}$ & -48.421 & 0.0152 & 0.000 & 14.382 & 0.0178 & 0.000 \\
\hline
\end{tabular}




\begin{tabular}{|l|c|c|c|c|c|c|}
\hline \multicolumn{1}{|c|}{ LFPR } & \multicolumn{3}{|c|}{ NSSO } & \multicolumn{3}{c|}{ IHDS-II } \\
\hline $\begin{array}{l}\text { marital }= \\
\text { widow(er)ed }\end{array}$ & t stat & std. err & Signif & t stat & std err & signif \\
\hline
\end{tabular}

With 'widowed/ widowered' as the reference, both NSSO and IHDS-II show that the categories 'married', 'divorced/ separated' and 'never married' are significant for LFPR. However, their respective coefficients have opposite signs from the two datasets. Thus, we can say that the two sources are not similar.

Table 12. t-test for LFPR using values of the education level variable

c) Decomposition of variable categories - Education level

\begin{tabular}{|c|c|c|c|c|c|c|}
\hline LFPR & \multicolumn{3}{|c|}{ NSSO } & \multicolumn{3}{c|}{ IHDS-II } \\
\hline & t stat & std. err & Signif & t stat & std err & signif \\
\hline $\begin{array}{c}\text { edulevel }= \\
\text { dipgrad }\end{array}$ & 47.563 & 0.0119 & 0.000 & 21.415 & 0.021 & 0.000 \\
\hline $\begin{array}{c}\text { edulevel }= \\
\text { niraakshar }\end{array}$ & 45.195 & 0.0077 & 0.000 & -20.431 & 0.023 & 0.000 \\
\hline $\begin{array}{c}\text { edulevel }= \\
\text { shaala }\end{array}$ & $\mathrm{n} / \mathrm{a}$ & $\mathrm{n} / \mathrm{a}$ & $\mathrm{n} / \mathrm{a}$ & $\mathrm{n} / \mathrm{a}$ & $\mathrm{n} / \mathrm{a}$ & $\mathrm{n} / \mathrm{a}$ \\
\hline
\end{tabular}

With 'shaala' as the reference, both NSSO and IHDS-II show that the categories 'dipgrad' and 'niraakshar' are significant for LFPR. The coefficients of 'dipgrad' are similar. However, the coefficients of 'niraakshar' have opposite signs from the two datasets. Thus, we can say that the two sources are not similar.

Table 13. t-test for LFPR using values of the relation to head variable

d) Decomposition of variable categories - Relation to household head

\begin{tabular}{|c|c|c|c|c|c|c|}
\hline LFPR & \multicolumn{5}{|c|}{ NSSO } & \multicolumn{3}{c|}{ IHDS-II } \\
\hline relation = self & 7.101 & 0.0138 & 0.000 & 34.000 & 0.02 & 0.000 \\
\hline $\begin{array}{c}\text { relation = } \\
\text { daughter-in-law }\end{array}$ & -78.440 & 0.0109 & 0.000 & -25.062 & 0.0162 & 0.000 \\
\hline $\begin{array}{c}\text { relation }= \\
\text { grandmother }\end{array}$ & -32.160 & 0.0375 & 0.000 & -9.980 & 0.051 & 0.000 \\
\hline $\begin{array}{c}\text { relation }= \\
\text { mother-in-law }\end{array}$ & -37.542 & 0.0236 & 0.000 & -0.280 & 0.1252 & 0.000 \\
\hline $\begin{array}{c}\text { relation }= \\
\text { servant }\end{array}$ & 0.000 & 0.0752 & 0.000 & -0.573 & 0.1938 & 0.000 \\
\hline $\begin{array}{c}\text { relation }= \\
\text { daughter }\end{array}$ & -87.379 & 0.0103 & 0.000 & -10.878 & 0.0148 & 0.685 \\
\hline $\begin{array}{c}\text { relation }=\text { wife } \\
\text { n/a }\end{array}$ & $\mathrm{n} / \mathrm{a}$ & $\mathrm{n} / \mathrm{a}$ & $\mathrm{n} / \mathrm{a}$ & $\mathrm{n} / \mathrm{a}$ & $\mathrm{n} / \mathrm{a}$ \\
\hline
\end{tabular}

With 'wife' as the reference, both NSSO and IHDS-II show that the categories 'self , 'daughter-in-law', 'mother-in-law', 'servant' and 'daughter' are significant for LFPR. The coefficients have the same signs from the two datasets or are too small to make a difference. Thus, we can say that the two sources are similar.

Table 14. t-test for LFPR using values of the religion variable

e) Decomposition of variable categories - Religion

\begin{tabular}{|c|c|c|c|c|c|c|}
\hline LFPR & \multicolumn{3}{|c|}{ NSSO } & \multicolumn{3}{c|}{ IHDS-II } \\
\hline $\begin{array}{c}\text { religion }= \\
\text { buddhism }\end{array}$ & 10.967 & 0.042 & 0.000 & -1.161 & 0.062 & 0.000 \\
\hline $\begin{array}{c}\text { religion }= \\
\text { christianity }\end{array}$ & 16.771 & 0.029 & 0.000 & -1.232 & 0.050 & 0.000 \\
\hline $\begin{array}{c}\text { religion }= \\
\text { islam }\end{array}$ & -12.261 & 0.028 & 0.000 & 2.680 & 0.046 & 0.000 \\
\hline $\begin{array}{c}\text { religion }= \\
\text { Jainism }\end{array}$ & -2.309 & 0.060 & 0.000 & 0.800 & 0.081 & 0.000 \\
\hline $\begin{array}{c}\text { relation }= \\
\text { Hinduism }\end{array}$ & $\mathrm{n} / \mathrm{a}$ & $\mathrm{n} / \mathrm{a}$ & $\mathrm{n} / \mathrm{a}$ & $\mathrm{n} / \mathrm{a}$ & $\mathrm{n} / \mathrm{a}$ & $\mathrm{n} / \mathrm{a}$ \\
\hline
\end{tabular}


With 'Hinduism' as the reference, both NSSO and IHDS-II show that the categories 'Buddhism', 'Christianity', 'Islam' and 'Jainism' are significant for LFPR. However, their respective coefficients have opposite signs from the two datasets. Thus, we can say that the two sources are not similar.

Table 15. t-test for LFPR using values of the social group variable f) Decomposition of variable categories - Social group

\begin{tabular}{|c|c|c|c|c|c|c|}
\hline LFPR & \multicolumn{3}{|c|}{ NSSO } & \multicolumn{3}{c|}{ IHDS-II } \\
\hline & t stat & std. err & Signif & t stat & std err & signif \\
\hline social = obc & -1.901 & 0.0242 & 0.000 & 12.184 & 0.009 & 0.000 \\
\hline social = sc/st & -3.034 & 0.0356 & 0.000 & 23.608 & 0.010 & 0.000 \\
\hline $\begin{array}{c}\text { social = } \\
\text { general }\end{array}$ & $\mathrm{n} / \mathrm{a}$ & $\mathrm{n} / \mathrm{a}$ & $\mathrm{n} / \mathrm{a}$ & $\mathrm{n} / \mathrm{a}$ & $\mathrm{n} / \mathrm{a}$ & $\mathrm{n} / \mathrm{a}$ \\
\hline
\end{tabular}

With 'General' as the reference, both NSSO and IHDS-II show that the categories ' $O B C$ ' and 'SC/ST' are significant for LFPR. However, their respective coefficients have opposite signs from the two datasets. Thus, we can say that the two sources are not similar.

Table 16. t-test for LFPR using values of the household size variable

g) Decomposition of variable categories - Household size

\begin{tabular}{|c|c|c|c|c|c|c|}
\hline LFPR & \multicolumn{3}{|c|}{ NSSO } & \multicolumn{3}{c|}{ IHDS-II } \\
\hline & t stat & std. err & Signif & t stat & std err & Signif \\
\hline hh_size & -7.857 & 0.001 & 0.000 & 1785.714 & 0.003 & 0.000 \\
\hline
\end{tabular}

As an integer variable, this does not require a reference category. Both NSSO and IHDS-II show that it is significant for LFPR. However, their coefficients have opposite signs from the two datasets. Thus, we can say that the two sources are not similar.

\section{Combination of all variables}

Next, we consider a combination of all variables together. In the Probit model, along with the individual variables, we include the interaction effects as well. The table below shows the results of the individual variables and their interaction effects.

Table 17. Probit analysis for LFPR using a combination of all variables

\begin{tabular}{|c|c|c|c|c|}
\hline LFPR & \multicolumn{2}{|c|}{ NSSO } & \multicolumn{2}{c|}{ IHDS-II } \\
\hline Variable & $\mathrm{X}^{2}$ & Signif & $\mathrm{X}^{2}$ & Signif \\
\hline Sector & 235.467 & .000 & 26.239 & .000 \\
\hline Marital & 108.356 & .000 & 141.697 & .000 \\
\hline Education & 614.639 & .000 & 246.527 & .000 \\
\hline Relation to head & 456.015 & .000 & 178.986 & .000 \\
\hline Religion & 270.778 & .000 & 21.216 & .000 \\
\hline Social & 62.097 & .000 & 131.145 & .000 \\
\hline Household size & .005 & .944 & .044 & 0.833 \\
\hline $\begin{array}{c}\text { sector * marital * } \\
\text { edulevel * } \\
\text { relation * religion } \\
\text { * social * hh_size }\end{array}$ & 2858.637 & 0.000 & 1294.890 & .254 \\
\hline
\end{tabular}

For LFPR, 'household size' is not significant in either NSSO or IHDS-II. All other variables are significant in both. The interaction is significant as per NSSO and not significant as per IHDS-II. Considering this discrepancy, one can say that the two sources are not analogous to each other.

\section{Sub-section 4C - Tables for SPUR statistical analysis}

\section{Determination of overall significance of factors for SPUR}

When we run separate Probit tests, with SPUR ('unemp') as the dependent variable, we get the following results. 
Table 18. Results of Probit analysis to test for variables significant for SPUR

\begin{tabular}{|c|c|c|c|c|}
\hline SPUR & \multicolumn{2}{|c|}{ NSSO } & \multicolumn{2}{c|}{ IHDS-II } \\
\hline & $\mathrm{X}^{2}$ & Signif & $\mathrm{X}^{2}$ & Signif \\
\hline Sector & 71.175 & 0.000 & 32.292 & 0.000 \\
\hline Marital & 1778.664 & 0.000 & 3167.527 & 0.000 \\
\hline Education & 2534.209 & 0.000 & 1100.663 & 0.000 \\
\hline Relation to head & 1954.019 & 0.000 & 1151.176 & 0.000 \\
\hline Religion & 374.693 & 0.000 & 112.665 & 0.000 \\
\hline Social group & 146.911 & 0.000 & 6273953.453 & 0.000 \\
\hline Household size & 100.998 & 0.000 & 2.525 & 0.112 \\
\hline
\end{tabular}

Here too, we see that the $\mathrm{X}^{2}$ values are very different from one another. More importantly, while we see that in NSSO, all variables are significant, in IHDS-II, the variable 'household size' is not significant. Considering this difference, one can say that the two datasets give dissimilar results for 'unemployment'.

\section{Identification of categories significant for SPUR}

The earlier test assessed the relative importance of each factor at an overall level. Next, we perform ttests using individual variables, by breaking each categorical variable into its various categories. This will help to determine respective coefficients.

Table 19. t-test for SPUR using values of the sector variable

a) Decomposition of variable categories - Sector - urban (reference), rural

\begin{tabular}{|c|c|c|c|c|c|c|}
\hline SPUR & \multicolumn{5}{|c|}{ NSSO } & \multicolumn{3}{c|}{ IHDS-II } \\
\hline $\begin{array}{c}\text { sector }= \\
\text { rural }\end{array}$ & t stat & std. err & Signif & t stat & std err & Signif \\
\hline $\begin{array}{c}\text { sector }= \\
\text { urban }\end{array}$ & -8.443 & 0.0167 & 0.000 & -5.677 & 0.0266 & 0.000 \\
\hline
\end{tabular}

With 'urban' as the reference, both NSSO and IHDS-II show that rural is significant for SPUR and their coefficients are very similar. The negative sign indicates that belonging to the rural sector decreases the likelihood of unemployment vis-a-vis the urban sector.

Table 20. t-test for SPUR using values of the marital status variable b) Decomposition of variable categories - Marital status

\begin{tabular}{|c|c|c|c|c|c|c|}
\hline SPUR & \multicolumn{3}{|c|}{ NSSO } & \multicolumn{3}{c|}{ IHDS-II } \\
\hline $\begin{array}{c}\text { marital = } \\
\text { divorced/ } \\
\text { separated }\end{array}$ & t stat & std. err & Signif & t stat & std err & signif \\
\hline $\begin{array}{c}\text { marital = } \\
\text { married }\end{array}$ & 5.172 & 0.1039 & 0.000 & 3.629 & 0.1174 & 0.000 \\
\hline $\begin{array}{c}\text { marital = } \\
\text { never } \\
\text { married }\end{array}$ & 16.465 & 0.0679 & 0.000 & 16.483 & 0.0617 & 0.000 \\
\hline $\begin{array}{c}\text { marital = } \\
\text { widow(er)ed }\end{array}$ & $\mathrm{n} / \mathrm{a}$ & $\mathrm{n} / \mathrm{a}$ & $\mathrm{n} / \mathrm{a}$ & $\mathrm{n} / \mathrm{a}$ & $\mathrm{n} / \mathrm{a}$ & $\mathrm{n} / \mathrm{a}$ \\
\hline
\end{tabular}

With 'widowed/ widowered' as the reference, both NSSO and IHDS-II show that the categories 'married', 'divorced/ separated' and 'never married' are significant for SPUR. The coefficients of 'divorced/ separated' and 'never married' are similar. However, the coefficients of 'married' have opposite signs from the two datasets. Thus, we can say that the two sources are not similar.

Table 21. t-test for SPUR using values of the education level variable c) Decomposition of variable categories - Education level

\begin{tabular}{|c|c|c|c|c|c|c|}
\hline SPUR & \multicolumn{3}{|c|}{ NSSO } & \multicolumn{3}{c|}{ IHDS-II } \\
\hline & t stat & std. err & Signif & t stat & std err & signif \\
\hline $\begin{array}{c}\text { edulevel }= \\
\text { dipgrad }\end{array}$ & 40.408 & 0.0196 & 0.000 & 25.814 & 0.013 & 0.000 \\
\hline
\end{tabular}




\begin{tabular}{|c|c|c|c|c|c|c|}
\hline SPUR & \multicolumn{3}{|c|}{ NSSO } & \multicolumn{3}{c|}{ IHDS-II } \\
\hline $\begin{array}{c}\text { edulevel }= \\
\text { niraakshar }\end{array}$ & -19.515 & 0.0309 & 0 & 11.200 & 0.008 & 0.000 \\
\hline $\begin{array}{c}\text { edulevel }= \\
\text { shaala }\end{array}$ & n/a & n/a & n/a & n/a & n/a & 0.000 \\
\hline
\end{tabular}

With 'shaala' as the reference, both NSSO and IHDS-II show that the categories 'dipgrad' and 'niraakshar' are significant for SPUR. The coefficients of 'dipgrad' are similar. However, the coefficients of 'niraakshar' have opposite signs from the two datasets. Thus, we can say that the two sources are not similar.

Table 22. t-test for SPUR using values of the relation to head variable

d) Decomposition of variable categories - Relation to household head

\begin{tabular}{|c|c|c|c|c|c|c|}
\hline SPUR & \multicolumn{3}{|c|}{ NSSO } & \multicolumn{3}{c|}{ IHDS-II } \\
\hline relation = self & -11.540 & 0.0526 & 0.085 & -0.559 & 0.111 & 0.085 \\
\hline $\begin{array}{c}\text { relation }= \\
\text { daughter-in- } \\
\text { law }\end{array}$ & 12.302 & 0.0278 & 0.000 & 1.583 & 0.0638 & 0.000 \\
\hline $\begin{array}{c}\text { relation }= \\
\text { grandmother }\end{array}$ & 6.978 & 0.0642 & 0.000 & 11.511 & 0.0834 & 0.000 \\
\hline $\begin{array}{c}\text { relation = } \\
\text { mother-in-law }\end{array}$ & -3.960 & 0.1192 & 0.021 & 1.143 & 0.3657 & 0.000 \\
\hline $\begin{array}{c}\text { relation }= \\
\text { servant }\end{array}$ & 0.000 & 0.2545 & 0.436 & -0.001 & 3752.135 & 0.021 \\
\hline $\begin{array}{c}\text { relation }= \\
\text { daughter }\end{array}$ & 32.987 & 0.0231 & 0.000 & 28.398 & 0.0412 & 0.000 \\
\hline relation = wife & n/a & n/a & n/a & n/a & n/a & n/a \\
\hline
\end{tabular}

With 'wife' as the reference, both NSSO and IHDS-II show that the categories 'daughter-in-law', 'mother-in-law' and 'daughter' are significant for SPUR. The coefficients have the same signs from the two datasets. However, in both cases, the category 'self is not significant. Also, in NSSO, 'servant' is not significant whereas in IHDS-II, it is significant. Thus, we can say that the two sources are similar.

Table 23. t-test for SPUR using values of the religion variable

e) Decomposition of variable categories - Religion

\begin{tabular}{|c|c|c|c|c|c|c|}
\hline SPUR & \multicolumn{3}{|c|}{ NSSO } & \multicolumn{3}{c|}{ IHDS-II } \\
\hline $\begin{array}{c}\text { religion }= \\
\text { Buddhism }\end{array}$ & 1.473 & 0.104 & 0.000 & 0.179 & 0.134 & 0.000 \\
\hline $\begin{array}{c}\text { religion }= \\
\text { christianity }\end{array}$ & 9.440 & 0.068 & 0.000 & -3.987 & 0.095 & 0.000 \\
\hline $\begin{array}{c}\text { religion }= \\
\text { islam }\end{array}$ & 4.142 & 0.069 & 0.000 & -0.788 & 0.090 & 0.000 \\
\hline $\begin{array}{c}\text { religion }= \\
\text { Jainism }\end{array}$ & -0.185 & 0.173 & 0.000 & -0.732 & 0.167 & 0.000 \\
\hline $\begin{array}{c}\text { religion }= \\
\text { Hinduism }\end{array}$ & $\mathrm{n} / \mathrm{a}$ & $\mathrm{n} / \mathrm{a}$ & 0.000 & $\mathrm{n} / \mathrm{a}$ & $\mathrm{n} / \mathrm{a}$ & $\mathrm{n} / \mathrm{a}$ \\
\hline
\end{tabular}

With 'Hinduism' as the reference, both NSSO and IHDS-II show that the categories 'Buddhism', 'Christianity', 'Islam' and 'Jainism' are significant for SPUR. The coefficients of 'Buddhism' \& 'Jainism' are similar. However, the coefficients of the other two categories have opposite signs. Thus, we can say that the two sources are not similar.

Table 24. t-test for SPUR using values of the social group variable

f) Decomposition of variable categories - Social group

\begin{tabular}{|c|c|c|c|c|c|c|}
\hline SPUR & \multicolumn{3}{|c|}{ NSSO } & \multicolumn{3}{c|}{ IHDS-II } \\
\hline & t stat & std. err & Signif & t stat & std err & signif \\
\hline social = obc & 11.364 & 0.011 & 0.000 & -4.167 & 0.012 & 0.000 \\
\hline social = sc/st & 6.376 & 0.015 & 0.000 & n/a & n/a & n/a \\
\hline
\end{tabular}




\begin{tabular}{|c|c|c|c|c|c|c|}
\hline SPUR & \multicolumn{3}{|c|}{ NSSO } & \multicolumn{3}{c|}{ IHDS-II } \\
\hline & t stat & std. err & Signif & t stat & std err & signif \\
\hline $\begin{array}{l}\text { social }= \\
\text { general }\end{array}$ & $\mathrm{n} / \mathrm{a}$ & $\mathrm{n} / \mathrm{a}$ & $\mathrm{n} / \mathrm{a}$ & $\mathrm{n} / \mathrm{a}$ & $\mathrm{n} / \mathrm{a}$ & $\mathrm{n} / \mathrm{a}$ \\
\hline
\end{tabular}

With 'General' as the reference, both NSSO and IHDS-II show that the categories ' $O B C$ ' and 'SC/ST' are significant for SPUR. However, their respective coefficients have opposite signs from the two datasets. Thus, we can say that the two sources are not similar.

Table 25. t-test for SPUR using values of the household size variable g) Decomposition of variable categories - Household size

\begin{tabular}{|c|c|c|c|c|c|c|}
\hline SPUR & \multicolumn{3}{|c|}{ NSSO } & \multicolumn{3}{c|}{ IHDS-II } \\
\hline & t stat & std. err & Signif & t stat & std err & Signif \\
\hline hh_size & -10.278 & 0.004 & 0.000 & -28.462 & 0.001 & 0.000 \\
\hline
\end{tabular}

As an integer variable, this does not require a reference category. Both NSSO and IHDS-II show that it is significant for SPUR. Their coefficients have the same sign from the two datasets. Thus, we can say that the two sources are similar.

\section{Combination of all variables}

Next, we consider a combination of all variables together. In the Probit model, along with the individual variables, we include the interaction effects as well. The table below shows the results of the individual variables and their interaction effects.

Table 26. Probit analysis for SPUR using a combination of all variables

\begin{tabular}{|c|c|c|c|c|}
\hline SPUR & \multicolumn{2}{|c|}{ NSSO } & \multicolumn{2}{c|}{ IHDS-II } \\
\hline Variable & $\mathrm{X}^{2}$ & Signif & $\mathrm{X}^{2}$ & Signif \\
\hline Sector & 6.961 & .008 & .455 & .500 \\
\hline Marital & 5.738 & .220 & 2.813 & .590 \\
\hline Education & 251.190 & .000 & 28.366 & .000 \\
\hline $\begin{array}{c}\text { Relation to } \\
\text { head }\end{array}$ & 72.655 & .000 & 5.875 & .882 \\
\hline Religion & 7.412 & .284 & 9.053 & .614 \\
\hline $\begin{array}{c}\text { Social } \\
\text { Household } \\
\text { size }\end{array}$ & 30.268 & .000 & 3.560 & .767 \\
\hline $\begin{array}{c}\text { sector * } \\
\text { marital } \\
\text { edulevel } \\
\text { relation } \\
\text { religion } \\
\text { social } \\
\text { hh_size }\end{array}$ & 0.276 & 0.599 & .088 & 1.000 \\
\hline
\end{tabular}

For SPUR, only 'education' is significant in IHDS-II. Only 'sector', 'education' and 'relation to head' are significant as per NSSO. Considering this discrepancy, one can say that the two sources are not analogous to each other.

\section{Sub-section 4D - Tests for normality of distributions}

Finally, we conduct the Kolmogorov-Smirnov (K-S) test on the annual income variable to test whether its distribution is normal. We do it separately on the two data sources. After these 1-sample tests, we combine the two sources and perform a 2-sample test. 


\section{Separate 1-sample K-S tests on annual income}

Table 27. Results of independent 1-sample K-S tests on annual income

\begin{tabular}{|c|c|c|}
\hline Variable & NSSO & IHDS-II \\
\hline Sample size (N) & 52,456 & 40,950 \\
\hline Mean (Avg. value) & 59,379 & 40,397 \\
\hline Standard deviation & 159,801 & 55,232 \\
\hline Kolmogorov-Smirnov Z & 66.945 & 65.658 \\
\hline $\begin{array}{c}\text { Asymptotic significance (2- } \\
\text { tailed) }\end{array}$ & .000 & .000 \\
\hline
\end{tabular}

Here, both NSSO \& IHDS-II have almost identical values of the Z statistic. Both values are significant. NSSO has a much greater standard deviation than IHDS-II. We infer that the income distributions of both data sources follow a normal distribution and are comparable.

\section{Combined 2-sample K-S test}

For the two-sample test, we take the 'income' values from both sources. Since this test requires a grouping variable, we code NSSO as ' 1 ' and IHDS-II as ' 2 '. From the table, we see that the K-S statistic is significant. So, we infer that the two samples are from the same distribution. That suggests that the income distribution of both, NSSO and IHDS-II is normal.

Table 28. Results of 2-sample K-S tests on annual income

\begin{tabular}{|c|c|}
\hline Variable & 2-sample results \\
\hline Sample size (N) & 93,406 \\
\hline Mann-Whitney U & $390,990,666$ \\
\hline Kolmogorov-Smirnov Z & 78.645 \\
\hline Asymptotic significance (2-tailed) & .000 \\
\hline
\end{tabular}

\section{Limitations and conclusions}

This study has two important limitations. One, it considers only two sources of data, both of which have been the subject of criticism over the lack of reliability of the data. For a stronger comparison, one must take 3 data sources into account and compare them. That will bring greater confidence to the data validation exercise. Singh (2017) is a good example of a comparative study, which takes many major states of India to carry out benchmarking. Two, while the study points out all aspects where the two datasets corroborate or don't corroborate each other, it offers no explanation in cases where the results are dissimilar. This is especially true of the income variable. Both, NSSO and IHDS-II have different methods to estimate and report incomes. This paper is an attempt to adjust them to a common metric. However, such an approach involves its own assumptions, as we have pointed out earlier. Given the sensitive nature of data related to economic status, establishment of those assumptions is outside the scope of this study.

In conclusion, one can state that both NSSO and IHDS-II have fairly large datasets. Their coverages are slightly different in the sense that the former has a smaller proportion of rural households (58\%) than the latter (65\%). On other demographic factors, both sources are largely similar. Their results related to employment status are almost identical, which suggests overall congruence between them. Hence, the overall LFPR and SPUR from the two sources are almost identical. With respect to LFPR, all factors - sector, marital status, education, relation to head, religion, social group and household size - are significant in both datasets. This result is common to both data sources. However, with respect to SPUR, there is an important difference. In IHDS-II, the variable 'household size' is not significant whereas it is significant in NSSO. In this sense, the two sources are not comparable. One of the reasons for this could be multicollinearity i.e. interaction among the variables. So, we perform one more test, taking all variables and also including their interaction effect. What we observe is that for LFPR, both the data sources are similar, such that 6 out of 7 variables are significant (with the $7^{\text {th }}$ being household size). For SPUR, one observes starkly different results. Except for 'education', all variables are insignificant in IHDS-II. NSSO is not much better with only 'sector' and 'relation to head' being significant.

When we conduct the 1-sample K-S test on the income variable individually, we see that both data sources have a normal distribution. When we conduct the 2 -sample K-S test together on the income variable, we see that both samples come from the same distribution. So, this result is valid.

Considering the series of tests above and their corresponding results, the summary is that NSSO and IHDS-II datasets are more dissimilar than similar. This implies that studies based on the two are likely to give different results. The future scope for research based on this is to study the factors driving 'unemployment' more closely. It will necessitate standardisation of incomes, without which statistical analyses will not 
produce reliable results. That area remains unexplored in the Indian context. Only after we address this can we build the necessary confidence in a comparison exercise.

\section{References}

1. Minhas, B (1988), 'Validation of Large Scale Sample Survey Data Case of NSS Estimates of Household Consumption Expenditure', Sankhyā: The Indian Journal of Statistics, Series B, Vol. 50, No. 3, pp. 49 - 63.

2. Sorensen, H, Sabroe, S \& Olsen, J (1996), 'A Framework for Evaluation of Secondary Data Sources for Epidemiological Research', International Journal of Epidemiology, Vol. 25, No. 2, pp. 435 - 442.

3. Sundaram, K\& Tendulkar, S (2001), 'NAS-NSS Estimates of Private Consumption for Poverty Estimation: A Disaggregated Comparison for 1993-94', Economic and Political Weekly, Vol. 36, No. 2, pp. 119 - 129.

4. Choudhury, $M$ (2002), 'Potential Selectivity Bias in Data: Evaluation of a Firm-Level Database on Indian Industry', Economic and Political Weekly, Series B, Vol. 37, No. 8, pp. 757 - 766.

5. Hirway, I (2002), 'Employment and Unemployment Situation in 1990s: How Good Are NSS Data?', Economic and Political Weekly, Vol. 37, No. 21, pp. $2027-2036$.

6. Bhattacharya, K (2007), 'How Good is the Bankscope Database? A Cross-Validation Exercise with Correction Factors for Market Concentration Measures', Bureau of Indian Standards, No. 133, 2003.

7. Berkhout, J \& Lowery, D (2008), 'Counting organized interests in the European Union: a comparison of data sources', Journal of European Public Policy, Vol. 15, No. 4, pp. 489 - 513.

8. Müller, K (2009), 'How robust are simulated employment effects of a legal minimum wage in Germany? A comparison of different data sources and assumptions', German Institute for Economic Research, No. 900, 2009.

9. Oldiges, C (2012), 'Cereal Consumption and Per Capita Income in India', Economic and Political Weekly, Vol. 47, No. 6, pp. 63 - 71.

10. Saikia, N\& Kulkarni, P (2012), 'Data for Research into Health Inequality in India Do We Have Enough?', Economic and Political Weekly, Vol. 51, No. 26, pp. $111-116$.

11. Singh, A. (2016), 'Do Technology Spillovers Accelerate Performance of Firms? Unravelling a Puzzle from Indian Manufacturing Industry'. Annals of the University Dunarea de Jos of Galati: Fascicle: XVII, Medicine, Vol. 22, No. 3.

12. Singh, A. (2016), 'R\&D spillovers \& productivity growth: evidence from Indian manufacturing', Indian Journal of Industrial Relations, Vol. 51, No. 4, pp. $563-579$.

13. Singh, A. (2017), 'Merge or Acquire-A Strategic Framework', Annals of the University Dunarea de Jos of Galati: Fascicle: XVII, Medicine, (3).

14. Singh, A. (2017), 'Does FDI Promote Productivity? A Deep Dive', Indian Journal of Industrial Relations, Vol. 52, No. 3.

15. Singh, A. (2017), 'Keeping It Simple: Comparative Analysis of TFP across Manufacturing Industries and Major States of India', Theoretical Economics Letters, Vol. 7, No. 06, pg. 1821.

16. Desai, S, Vanneman, R (2018), 'India Human Development Survey (IHDS), 2005', University of Maryland, National Council of Advanced Economic Research (NCAER).

17. Singh, A (2018), 'Does Size Matter? - The Effect of Size of Production Workers, Management Staff and Proprietors on Productivity', Theoretical Economics Letters, Vol. 8, No. 11, pg. 2290.

18. Sarkar, S, Sahoo, S \& Klasen, S (2018), 'Employment transitions of women in India: A panel analysis', World Development, Vol. 115, No. 3, pg. $291-309$. 